\title{
THE STATUS OF THE BALD EAGLE AND OSPREY IN GRAND TETON NATIONAL PARK AND VICINITY
}

Robert L. Eng, Professor of Wildlife Kurt Alt, Graduate Research Assistant Montana State University

\section{Objectives}

With the accelerated use of our national parks there is growing concern over the impact this increased visitation might have on their flora and fauna. For this reason it is important to gather baseline data on the biota for future management and interpretive programs. Two species of concern in Grand Teton National Park are the bald eagle (Haliaeetus leucocephalus) and osprey (Pandion haliaetus).

The objectives of this proposed two year study are to provide baseline data on the life history (breeding chronology, nesting success and food habits) of these birds, to provide quantitative data on numbers and distribution of breeders and non-breeders, to determine productivity, to locate actual and potential nesting areas and to assess response to human activities. The data collected on the bald eagle will be gathered from Grand Teton National Park, Yellowstone National Park and vicinity in the hopes of drawing some conclusions about the population in this area as a whole. Data on the bald eagle in Yellowstone National Park will be greatly facilitated from the work done by Jon Swenson in the years 1972, 1973 and 1974.

\section{Procedures}

During May, time was spent collecting and reviewing maps and 1 iterature regarding the study area and the two species of concern. Actual field work did not begin until June 13, 1978.

Considerable time was spent during this initial summer in becoming familiar with and locating nest sites in Grand Teton National Park and vicinity. This time was spent in a rubber raft, canoe with a 4-hp outboard, or on foot covering the Snake River and its major tributaries (Pacific Creek and the Buffalo and Gros Ventre Rivers) and searching the shorelines of Jackson, Leigh, Jenny, Emma Matilda, Two Ocean, Phelps and Lower Slide Lakes for possible nest sites (both bald eagle and osprey). A 15-60 X spotting scope and a pair of $7 \times 35 \times$ binoculars were used in making observations.

Three aerial surveys were made in a 150-hp Super Cub piloted by James Stradley who has had several years experience in locating eagle and 
osprey nests. These surveys were essential in gathering data on nest locations, chronological data on nesting, quantitative data on numbers and distribution of breeders and non-breeders, and in determining productivity in the Grand Teton and Yellowstone National Parks area. The initial flight, made on May 27, 1978, provided data on territory occupancy and helped establish the nest status of the bald eagle in Grand Teton and Yellowstone National Parks. It also provided data on territory occupancy and approximate nest initiation dates of osprey in Grand Teton National Park. The second flight, conducted on June 29, 1970, provided data on productivity of the bald eagle in Grand Teton and Yellowstone and also supplemented data on territory occupancy of osprey in Grand Teton National Park. The third and final flight, made July 30, 1978, provided data on productivity of osprey in Grand Teton National Park.

Some general osprey feeding sites have been located. Through the use of park records and personal observations the effects of fisherman concentration and of private and concessioned float trips on osprey nest sites and feeding areas are trying to be assessed.

During the first two weeks in September bald eagle and osprey nest site measurements were made and food remains collected. During this time four bald eagle nest trees were climbed to obtain measurements of the nest. Food item remnants from the nest were collected. By waiting until this time to collect these data, minimal observer disturbance was rendered at active nest sites.

\section{Results}

Locations of bald eagle territories in Grand Teton National Park, Yellowstone National Park and vicinity and osprey nests in Grand Teton National Park are shown in Figure 1. The bald eagle territories in Yellowstone National Park, with the exception of one located on the upper Snake River, were taken from Swenson (1975). In the study area (Grand Teton, Yellowstone and vicinity) there are a minimum of 27 bald eagle territories. Four of these territories are located within Grand Teton National Park and 15 within Yellowstone National Park. The remaining 8 territories are located within the vicinity of the two parks, 5 of these being just outside their boundaries. There were 22 osprey nests located in Grand Teton National Park, 16 of which had known activity in 1978. Three of the remaining nests had unknown status, that is, by the time these nests were located nest desertion could already have taken place.

Reproductive data for the bald eagle and osprey are summarized in Tables 1 and 2 , respectively. The definitions of the reproductive terms used in these tables are from Swenson's (1975) modification of Postupalsky's (1974) terminology describing raptor nest status and reproductive success. The figure in Table 1 which gives the number of bald eagles fledged in the vicinity of the two parks was determined in part by personal 
communications with Jon Swenson, Lee Stroups, Verland Taylor and John Weaver who reported two eagles fledged from the Cliff Lake nest, two eagles from the Red Rock Refuge, one eagle from the nest on Lower Slide Lake, and one eagle from the nest on the lower Snake River just south of Hoback, respectively. This year the brood size and productivity for bald eagles in Grand Teton National Park was less than that for Yellowstone National Park (Table 1). By considering the bald eagle productivity of Grand Teton, Yellowstone and vicinity as a whole a value higher than that of both parks was obtained. The figure in Table 2 which gives the number of active osprey nests on rivers includes a nest on Pacific Creek, near the Grand Teton National Park-Teton Wilderness boundary, reported as active by John Weaver (pers. comm.). During the second flight the osprey nest on Jackson Lake between Colter and Waterfalls Canyons contained 2 eggs. As seen in Table 2 there were about twice as many osprey nests located on lakes than on rivers in Grand Teton National Park, however, the brood size and productivity were slightly higher on rivers than on lakes. The total productivity (lakes and rivers) based on active nests for Grand Teton National Park was calculated to be .44 .

The dates of egg laying and hatching are estimates based upon data gathered from periodic visits to the nest sites. At the time the first flight was made bald eagles were in incubating postures in both parks. Osprey in Grand Teton National Park were also in an incubating posture in nests on the Snake River and Jackson, Leigh, and Emma Matilda Lakes. For this reason dates on egg laying and hatching are estimates based on fledging dates and estimated dates from previous studies and will not be presented at this time.

The first observed flight of the bald eagle cledged in Grand Teton this year was August 9 (pers. comm. Bill Gordon). The approximate fledging dates of the three eagles produced from the two nests on Hebgen Lake are July 10 from one nest (pers. comm. Aaron Hamilton) and July 11 from the other (pers. comm. Bob Wahl). The bald eagles produced from the nest on the upper Snake River in Yellowstone and from the nest on the lower Snake River near the Jackson airport fledged sometime between June 29 and July 30 . First observed flights for the young osprey from the two nests on the Snake River are on August 13 and 14. Osprey produced from nests on Jackson Lake had first observed flights between August 15 and 17 .

The height of bald eagle nests in trees ranged from 9.4 to 29.7 meters and averaged 17.4 meters. The average width (from the tree trunk to the outside edge of the nest), length (the perpendicular measurement to the width), and thickness (taken from the top of the nest to the bottom of the nest) of the four nests measured are $1.3 \mathrm{~m}, 2.1 \mathrm{~m}$, and 1 meter respectively. The heights of osprey nests ranged from 10 to 20 meters with an average heigth of 17.2 meters. 


\section{Conclusions}

The bald eagle productivity of 1.25 (active nests only) for Grand Teton National Park, Yellowstone National Park and the vicinity in 1978 was quite high when compared to .39 reported by Jon Swenson for Yellowstone National Park for the years 1972, 1973 and 1974. An error in calculating productivity based on active nests is that of classifying a nest, which was active early in the season, as occupied when the initial check is made. This could be a result of scheduling the first flight too late in the season. This problem can be minimized by calculating productivity based on occupied nests. This was done for these data and the value of .95 obtained is still much higher than Swenson's value of .23 based on the productivity of occupied nests during his three-year study.

The productivity (active nests) for osprey in Grand Teton National Park was calculated to be .43 . This value is less than that calculated by Swenson (.74) on osprey in Yellowstone National Park. Based on these preliminary data, continued osprey productivity in Grand Teton National Park at this rate would result in decline in the osprey population in this area.

\section{Acknowledgments}

I wish to thank Robert L. Eng, for supervision of the study, and Ken Diem, Bob Wood, Pete Hayden, Bill Barmore, Mary Meagher and Doug Houston for their cooperation with the project. I would also like to thank Jon Swenson for recommendations during the study. This project was funded through the University of Wyoming-National Park Service Research Center.

\section{Literature Cited}

Postupalsky, J, 1974. Raptor reproductive success: some problems with methods, criteria and terminology. Raptor Res. Rept. 2:21-31, 1974.

Swenson, J. E. 1975. Ecology of the bald eagle and osprey in Yellowstone National Park. M.S. Thesis, Montana State Univ,, Bozeman. 146 pp. 
Table 1. Reproduction of bald eagles in Grand Teton National Park, Yellowstone National Park and vicinity - 1978.

\begin{tabular}{lcccc}
\hline & GTNP & YNP & Vicinity & Total \\
\hline Territories observed & 4 & 15 & 9 & 28 \\
Occupied nests (A) & 4 & 8 & 9 & 21 \\
Active nests (B) & 2 & 6 & 8 & 16 \\
Successful nests (C) & 1 & 5 & 8 & 14 \\
*Young fledged (D) & 1 & 8 & 11 & $* * 20$ \\
Brood size (D/C) & 1 & 1.6 & 1.37 & 1.43 \\
Productivity (occupied) (D/A) & .25 & 1.0 & 1.22 & .95 \\
Productivity (active)(D/B) & .5 & 1.3 & 1.37 & 1.25 \\
\hline
\end{tabular}

*Young raised to advanced stage of development.

**'Two eaglets killed in a nest which blew down below GTNP are not

included in this total (pers. comm. Bob Oakleaf).

Table 2. Reproduction of osprey in Grand Teton National Park - 1978.

\begin{tabular}{lccc}
\hline & Lakes & Rivers & Total \\
\hline Nests observed & 15 & 7 & 22 \\
Active nests (A) & 10 & 6 & 16 \\
Successful nests (B) & 3 & 2 & 5 \\
Nest status unknown & 3 & 0 & 3 \\
Young fledged (C) & 4 & 3 & 7 \\
Brood size (C/B) & 1.3 & 1.5 & 1.4 \\
Productivity (active) (C/A) & .4 & .5 & .44 \\
\hline
\end{tabular}




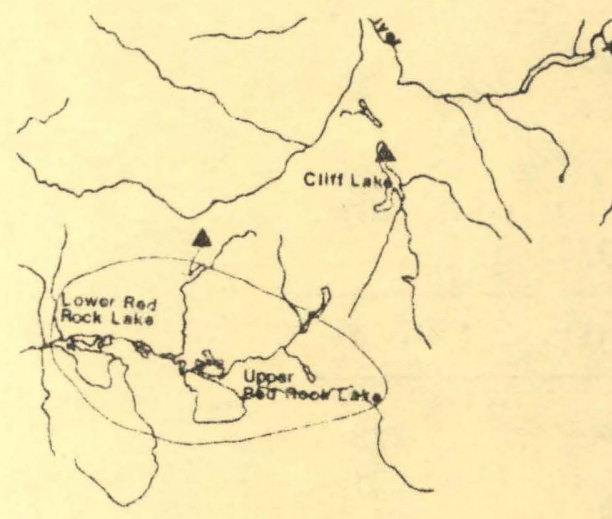

LE QEND

A BALD EAGLE TERRITORY

- osprey nest site
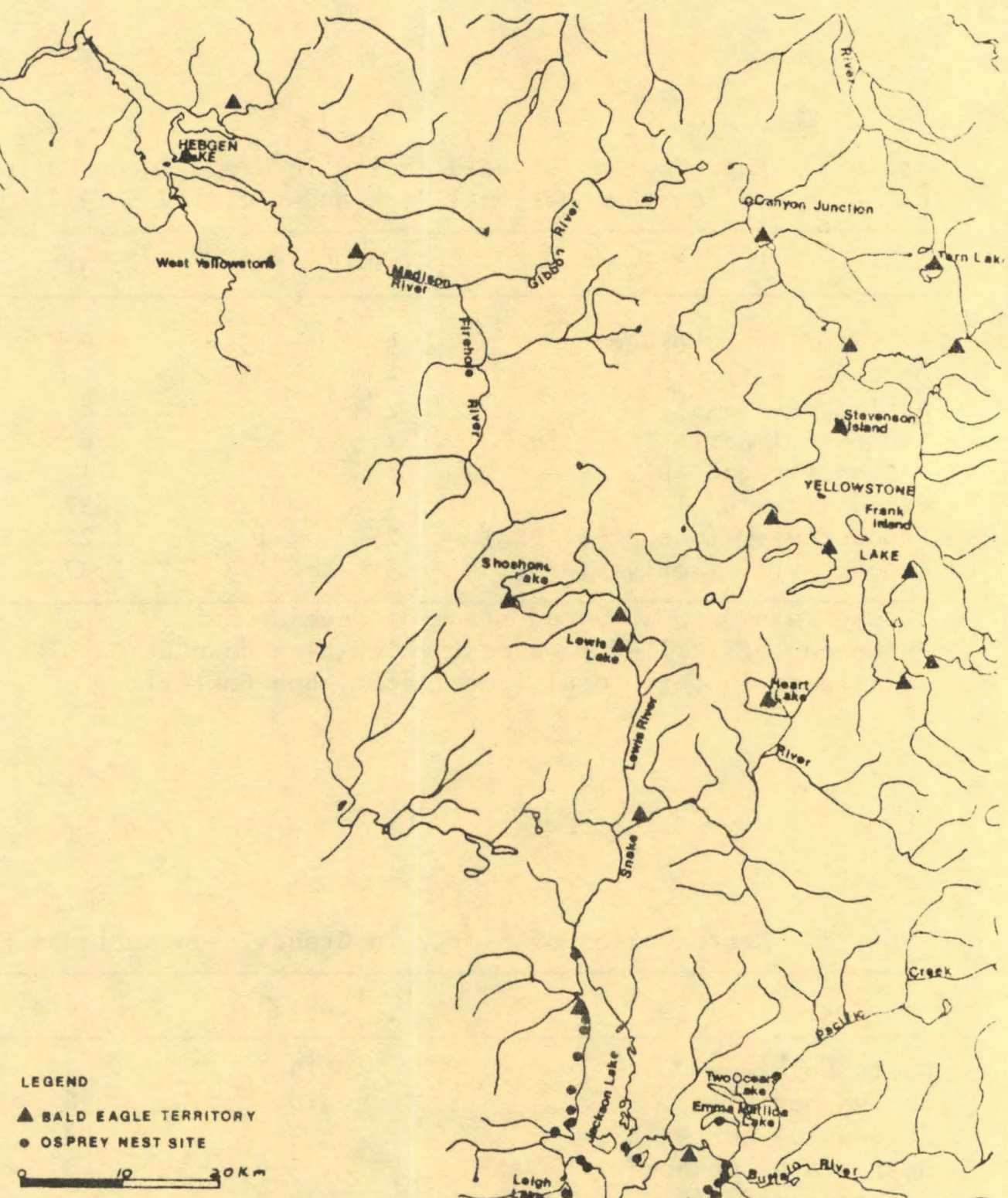

Figure 1. Map of bald eagle territories in Grand Teton National Park, Yellowstone National Park and vicinity and osprey nest sites in Grand Teton National Park.
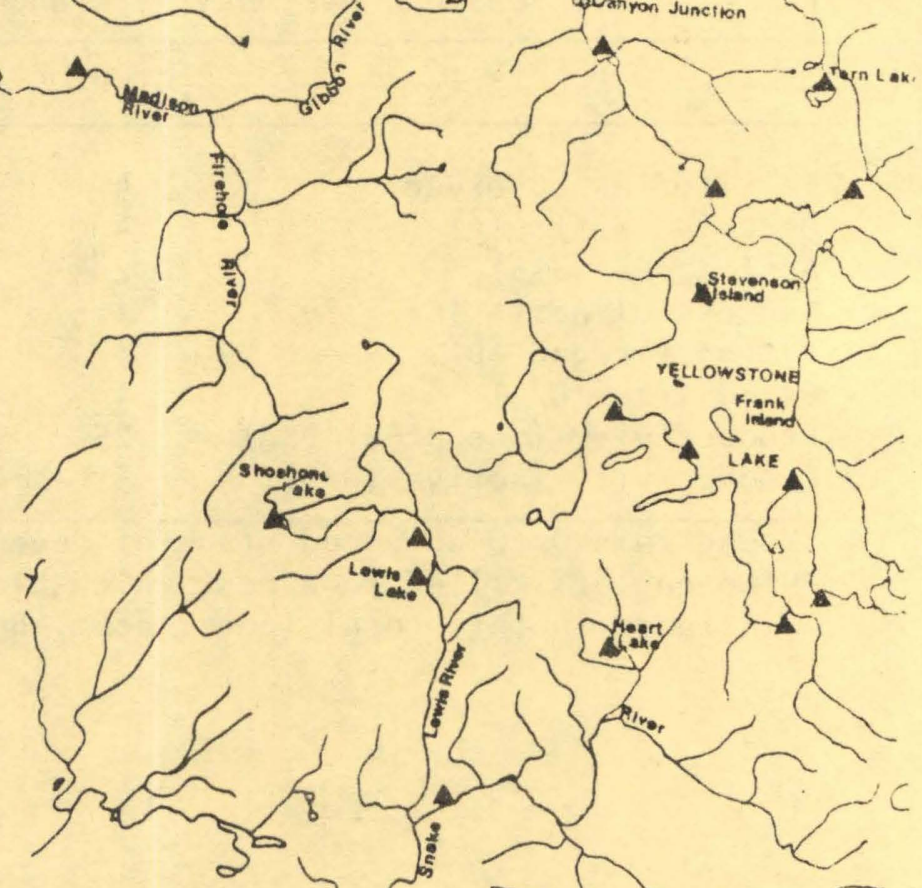